\title{
Simultaneous Analysis of Cytokines and Costimulatory Molecules Concentrations by ELISA Technique and of Probabilities of Measurable Concentrations of Interleukins IL-2, IL-4, IL-5, IL-6, CXCL8 (IL-8), IL-10, IL-13 Occurring in Plasma of Healthy Blood Donors
}

\author{
Klabusay Martin, ${ }^{1}$ Kohutova Viera, ${ }^{1}$ Coupek Petr,${ }^{2}$ Nenickova Marie, ${ }^{3}$ and Tesarova Eva ${ }^{3}$ \\ ${ }^{1}$ Laboratory of Flow Cytometry and Cellular Therapy, Department of Internal Medicine-Hematooncology, \\ University Hospital Brno, Jihlavska 20, 62500 Brno, Czech Republic \\ ${ }^{2}$ Division of Informatics, Czech Geological Survey, Leitnerova 22, 65869 Brno, Czech Republic \\ ${ }^{3}$ Transfusion Department and Blood Bank, University Hospital Brno, Jihlavska 20, 62500 Brno, Czech Republic
}

Received 14 April 2006; Revised 18 June 2006; Accepted 19 June 2006

Background. The cytokine network remarkably influences homeostasis. There is not a complex analysis describing physiological values of soluble cytokines in healthy individuals. Methods. Authors used the ELISA method to detect soluble cytokines and costimulatory molecules simultaneously in the plasma of 30 blood donors. Results. Data are shown as (a range of concentrations; median) IL-2 (0-74.48 pg/mL; 0), IL-4 (0-65.18 pg/mL; 0), IL-5 (0-86.69 pg/mL; 0), IL-6 (0-73.17 pg/mL; 0), IL-8 (0-74.8 pg/mL; $0)$, IL-10 (0-12.6 pg/mL; 0), IL-13 (0-3.9 pg/mL; 0), sCD40L (0-3.5 ng/mL; 0), and TNF- $\alpha$ (0-67.6; 0). For the IL-6 receptor, the concentration was $75.89 \pm 35.83 \mathrm{ng} / \mathrm{mL}$ (average $\pm \mathrm{SD}$ ), sCD23 $28.9 \pm 15.22 \mathrm{ng} / \mathrm{mL}$, and TGF $\beta 114.98 \pm 12.39 \mathrm{ng} / \mathrm{mL}$. A special approach was taken for the analysis of values, which had median 0 . A model for the probability of detectable level's occurrence for each interleukin was formulated with intervals of confidence. Conclusion. These results provide reference values for cytokine levels in the plasma of healthy individuals.

Copyright (c) 2006 Klabusay Martin et al. This is an open access article distributed under the Creative Commons Attribution License, which permits unrestricted use, distribution, and reproduction in any medium, provided the original work is properly cited.

\section{INTRODUCTION}

Cytokines are biologically active macromolecules of protein structure. They constitute a part of other signaling pathways and their functions are fully developed after binding to specific receptors. Cytokines act pleiotropically, are redundant, and act at minimal concentrations $(\mathrm{ng} / \mathrm{mL}$ to $\mathrm{pg} / \mathrm{mL}$ ). They regulate the expression of costimulatory and accessory molecules on the cell surface. Today, the term "cytokines" also includes other regulatory proteins, particularly monokines, interleukins, interferons, and growth factors, which can potentially be produced by every nuclear cell while their pleiotropic effects on various cells are maintained [1].

The cytokine receptors mostly bind cytokines with high affinity. They are expressed as inducible on the cell surface and their expression increases after activation. It is not easy to classify cytokines into groups because some molecules can be affiliated into more than one category. One of the cur- rent classifications divides cytokines on the basis of their functions: cytokines that regulate hematopoiesis (SCFstem cell factor, FLT3-ligand, interleukin-3, CSF-colonystimulating factors: G-CSF, GM-CSF and M-CSF, erythropoetin, thrombopoetin); interferons (IFN- $\alpha$, IFN- $\beta$, IFN- $\gamma$ ); cytokines that mostly regulate the functions of $\mathrm{B}$ - and $\mathrm{T}$ lymphocyte systems (cytokines of the $\mathrm{Th}_{1}$ subset: IL-2, 3, IFN- $\gamma$, and TNF, cytokines of the $\mathrm{Th}_{2}$ subset: IL-3, IL-4, IL5, IL-6, IL-10, and IL-13, cytokines produced by quenching cytotoxic $\mathrm{CD}^{+} \mathrm{T}$-lymphocytes and inductor helper Tlymphocytes-Th $\mathrm{T}_{3}$ subset: IL-10 and by transforming growth factor $\beta$ ); pluripotent inflammatory cytokines (IL-1 and IL6 ); tumor necrosis factors; chemokines (according to the original names IL-8, MIP-1- $\alpha, \beta$, RANTES, MCP-1, TARC, and others); and growth factors (TGF $\beta$, PDGF-plateletderived growth factor, FGF-fibroblast growth factor, VEGF-vascular endothelial growth factor, KGF-growth factor for keratinocytes, and others) [1]. The discovery and 
characterization of new cytokines are accompanied by the identification of genes similar to those of the previously described cytokines.

Hematooncology is one field in which the application of some cytokines has already found its place as a standard part of therapy: the use of recombinant hematopoietic growth factors (G-CSF and GM-CSF) for the CD34 ${ }^{+}$cell compartment mobilization, and the collection of PBSC (peripheral blood stem cells) for the transplantation of hematopoiesis and treatment of neutropenia [2, 3]. IL-2 and IFN- $\alpha$ are used in treating solid tumors (kidney cancer), chronic myeloid leukemia, and non-Hodgkin's lymphoma. Anticytokine therapy by infliximab (anti-TNF- $\alpha$ ) is used in rheumatology $[1,4,5]$.

The cytokine concentration in body fluid or tissue culture supernatants can be determined immunochemically with monoclonal antibodies (using ELISA, FIA, luminescent immunoanalysis, flow cytometry) or polyclonal antibodies, immunohistochemically, at the mRNA level, or by bioanalysis. When looking for a work that would refer to the physiological limits of cytokines, growth factors, or selected molecules, one encounters a lack of comprehensive information. In works describing various shifts in cytokine profile in both nononcological and oncological diagnoses or in post-transplant complications, the control group samples are analyzed, as well, but in the majority of cases the control group is not represented sufficiently; the cytokine concentration in vitro in cultured cell lines is preferred, or the work is selectively focused on a particular cytokine. The aim of our work is to provide an actual range of physiological values in a purposely selected group of objectively healthy individualsblood donors.

\section{METHODS}

\section{Material}

Thirty healthy donors, selected as whole blood donors in the Transfusion Department and Blood Bank, were included in the analysis ( 15 women and 15 men). The average age of the donors was 34 (median: 30.5, men: 32, women: 29). In regard to the distribution of blood groups, type 0 predominated $(n=13)$, followed by groups $\mathrm{A}(n=5), \mathrm{A} 1(n=4)$, $\mathrm{B}(n=4), \mathrm{A} 1 \mathrm{~B}(n=3)$, and there was one $\mathrm{AB}$ donor. The distribution of blood groups in the Rh system (D) correlated with the prevalence in the population.

All blood donors signed statements of informed consent before blood samples were taken, and experiments were approved by the Ethics Committee of the University Hospital, Brno, Czech Republic.

\section{Sample processing}

Samples were transported in test tubes with EDTA in an insulated box to the laboratory and processed within 2 hours. Plasma was obtained by centrifugation (10 min, $250 \mathrm{~g})$ and stored at $-80^{\circ} \mathrm{C}$ before the analysis.

\section{ELISA (enzyme-linked immunosorbent assay)}

Instant ELISA kits (Bender MedSystems GmBH, Austria) were used. The kits contained the microtitration plate with adsorbed conjugate of the mouse monoclonal antibody against determined antigens and nonspecific horseradish peroxidase. Every plate contained a doublet of seven standards for construction of the calibration curve and blank, and the $\mathrm{pH}$ of the washing phosphate-buffered saline (PBS) solution with $1 \%$ tween 20 was adjusted to 7.4 . A tetramethyl benzidine (TMB) solution served as the substrate for the redox reaction. Activity of the enzyme was stopped by $1 \mathrm{M}$ phosphoric acid and absorbance was measured at $450 \mathrm{~nm}$. The laboratory software Kim32 (Schoeller Pharma, Czech Republic) was used to evaluate the results.

\section{Evaluation}

Data were evaluated statistically with the R-language program. A special approach was taken to evaluate the data for interleukins with frequent zero-value occurrence. Correlation among particular cytokines and costimulatory molecules (IL-2-IL-13, TNF- $\alpha$, sIL-6-R, sCD23, sCD40L, and TGF $\beta 1$ ) were tested in a $12 \times 12$ matrix against one another and the Spearman order correlation coefficient was calculated. Gender and blood groups of subjects were tested with Kolmogorov-Smirnov nonparametric tests against the cytokines and costimulatory molecules concentrations. Because these methods test only the effect on isolated cytokines, logistic regression was used to model the effect of independent values of gender and blood group on combinations of cytokines.

\section{RESULTS}

From the data distribution, it was clear that the problem of zero values of interleukins could not be resolved by a standard statistical approach. A zero value was affixed to concentrations beneath the detection limit of the analysis, which means that values designated as zero in this case are not detectable using the relevant analysis but can in fact be positive.

The results were divided into two parts: concentrations of interleukins in the donor plasma and $\operatorname{TNF}-\alpha, \operatorname{TGF} \beta 1$, sIL-6R, sCD23, and sCD40L concentrations. The median of interleukin concentration, as well as the majority of measured values, was 0 (see Figure 1 ). To deal with the problem of "zero" values, a nonstandard strategy was chosen for evaluating the data. It was possible to calculate the probability of positive occurrence in the general population for IL2 through IL-13 cytokine levels, including confidence intervals. Although there were very few positive values (and there is an assumption that positive values will appear in a healthy population to a small extent), it was possible to calculate the probability of the positive value incidence in a healthy donor from 30 observations, including the confidence interval.

We describe the values which differed significantly from the majority of the measured data (remote and extreme), as noted in detail below. The summary of zero-value data 
TABle 1: Probabilities of occurence of detectable level of particular interleukin in plasma of healthy blood donors. $P$ is probability of nonzero values occurence of interleukin and confidence interval at $5 \%$ level, $\%$ of population shows proportion of blood donors with nondetectable level of particular interleukin and confidence interval at 5\% level, and detection limit shows limit for detecting particular interleukin in ELISA assay.

\begin{tabular}{|c|c|c|c|c|c|}
\hline & $P$ & $P$ interval & $\%$ of population & $\%$ interval & Detection limit \\
\hline IL-2 & .067 & $(.056 ; .147)$ & $93.3 \%$ & $(85.3 \% ; 94.4 \%)$ & $2.3 \mathrm{pg} / \mathrm{mL}$ \\
\hline IL-4 & .100 & $(.073 ; .204)$ & $90 \%$ & $(79.6 \% ; 92.7 \%)$ & $0.66 \mathrm{pg} / \mathrm{mL}$ \\
\hline IL-5 & .167 & $(.11 ; .147)$ & $83.3 \%$ & $(69.4 \% ; 89 \%)$ & $0.92 \mathrm{pg} / \mathrm{mL}$ \\
\hline IL-6 & .067 & $(.056 ; .147)$ & $93.3 \%$ & $(85.3 \% ; 94.4 \%)$ & $0.92 \mathrm{pg} / \mathrm{mL}$ \\
\hline CXCL8 & .167 & $(.11 ; .306)$ & $83.3 \%$ & $(69.4 \% ; 89 \%)$ & $7.26 \mathrm{pg} / \mathrm{mL}$ \\
\hline IL-10 & .033 & $(.038 ; .147)$ & $96.7 \%$ & $(91.6 \% ; 96.2 \%)$ & $0.66 \mathrm{pg} / \mathrm{mL}$ \\
\hline IL-13 & .100 & $(.073 ; .20)$ & $90 \%$ & $(79.6 \% ; 92.7 \%)$ & $0.99 \mathrm{pg} / \mathrm{mL}$ \\
\hline
\end{tabular}

TABLE 2: Medians and ranges of measured values of cytokines and costimulatory molecules (except interleukins). Percentage of population describes proportion of blood donors with nondetectable level of particular cytokine. Detection limit shows limit for detecting particular cytokine in ELISA assay.

\begin{tabular}{l|cccr}
\hline & Median & Range of values & \% of population & Detection limit \\
\hline TNF- $\alpha$ & $<1.65$ & $0-67.6 \mathrm{pg} / \mathrm{mL}$ & $52 \%$ & $1.65 \mathrm{pg} / \mathrm{mL}$ \\
TGF $\beta 1$ & 10.8 & $14.98 \pm 12.39 \mathrm{ng} / \mathrm{mL}$ & $3.5 \%$ & $0.06 \mathrm{ng} / \mathrm{mL}$ \\
sCD23 & 27.6 & $28.9 \pm 15.22 \mathrm{ng} / \mathrm{mL}$ & $7 \%$ & $3.3 \mathrm{ng} / \mathrm{mL}$ \\
sCD40L & $<0.062$ & $0-3.5 \mathrm{ng} / \mathrm{mL}$ & $71 \%$ & $0.062 \mathrm{ng} / \mathrm{mL}$ \\
sIL-6R & 68.75 & $75.89 \pm 35.83 \mathrm{ng} / \mathrm{mL}$ & $0 \%$ & $0.01 \mathrm{ng} / \mathrm{mL}$ \\
\hline
\end{tabular}

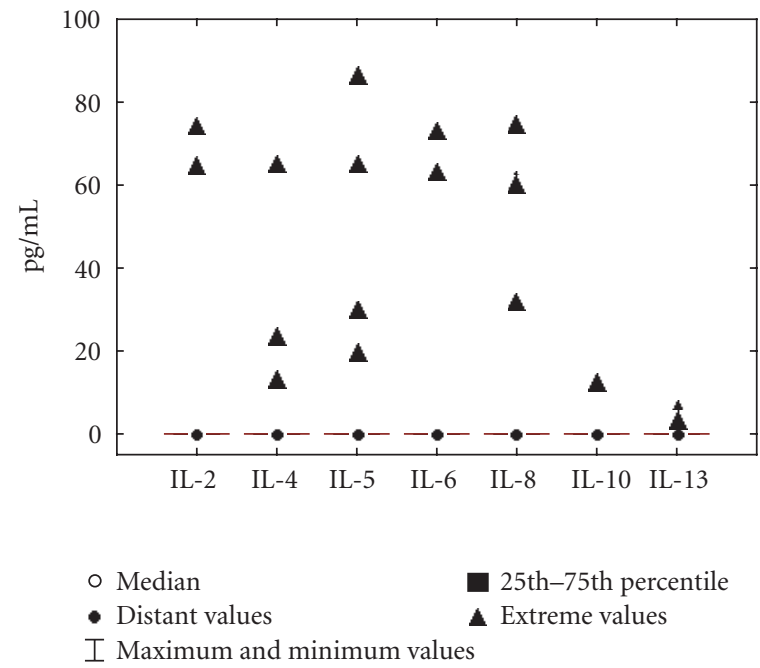

Figure 1: Plasma concentration of measured interleukins. The graph (box-and-whiskers plot) shows the median and extreme values of measured concentrations of interleukins IL-2, IL-4, IL-5, IL6 , IL-8, IL-10, and IL-13. There was no correlation among measured extreme values of different interleukins. All median values of interleukins were 0 . For the detection limits of particular assays, see Table 1.

probability for particular interleukins, including the confidence intervals and detection limits, is shown in Table 1. For instance, the $P=.067$ with an interval $(.056 ; .147)$ was calculated for IL-2, so the level of IL-2 for $93.3 \%$ of the population interval $(85.3 ; 94.4)$ will be below the detection limit. Nonzero values of IL-2 will be detected only in $5.6 \%$ to $14.7 \%$ of the population. The confidence intervals were constructed at the $5 \%$ level. The description is analogous for other interleukins.

As there were more detected values, standard statistical evaluation was possible for TNF- $\alpha$, TGF $\beta 1$, sIL-6R, sCD23, and sCD40L parameters (see Table 2). A graphic presentation of the data, including the remote and extreme values, is shown in Figures 2 and 3. For other characteristics of the blood donors groups, see Table 3.

\section{Interleukins (IL-2, IL-4, IL-5, IL-6, CXCL8, IL-10, IL-13)}

A certain amount of interleukins in plasma was measured in only a few donors. Medians were equal to 0 . The measured extreme values are shown in Figure 1. There were 2 positive donors (men of approximately the same age: 41 and 42 years) with regard to IL-2 (values 64.86 and $74.48 \mathrm{pg} / \mathrm{mL}$ ), the former with detected level $x$ of IL-5, sIL-6R, soluble CD23 and CD40L molecules, and TGF $\beta 1$ simultaneously, and the latter with TNF- $\alpha$, sIL-6R, and TGF $\beta 1$. The majority of values were below the detection limit of the analysis (DL), which in this case was $2.3 \mathrm{pg} / \mathrm{mL}$.

The IL- 4 above DL $(0.66 \mathrm{pg} / \mathrm{mL})$ level was found in 2 men and 1 woman; sIL-6R, sCD23, TGF $\beta 1$ were detected in the men simultaneously and additionally IL-13 in 1 woman.

Interleukin-5 above DL $1.45 \mathrm{pg} / \mathrm{mL}$ was measured in 2 men and 2 women. The men had measurable amounts of sCD40L, TGF $\beta 1$, sIL-6R, and sCD23 in plasma, while they differed in the presence of IL-2 versus IL-6 + CXCL8. In one woman, IL-10 and sIL-6R were above DL.

Two men had IL-6 levels above DL $0.92 \mathrm{pg} / \mathrm{mL}$, and additionally they were positive for sIL-6R, sCD23, and TGF $\beta 1$; 
TABLE 3: Average values (with standard deviations) of other characteristics of blood donors.

\begin{tabular}{lccccccc}
\hline Gender & No & $\begin{array}{l}\text { Age (years }) \\
(\mathrm{av} \pm \mathrm{SD})\end{array}$ & $\begin{array}{l}\text { Haemoglobin } \\
(\mathrm{g} / \mathrm{L})(\mathrm{av} \pm \mathrm{SD})\end{array}$ & $\begin{array}{l}\text { Leucocyte count } \\
\left(\times 10^{9} / \mathrm{L}\right)(\mathrm{av} \pm \mathrm{SD})\end{array}$ & $\begin{array}{l}\text { Blood pressure } \\
(\mathrm{mm} \mathrm{Hg})(\mathrm{av} \pm \mathrm{SD})\end{array}$ & $\begin{array}{l}\text { ALT }(\mu \mathrm{kat} / \mathrm{L}) \\
(\mathrm{av} \pm \mathrm{SD})\end{array}$ & $\begin{array}{l}\text { Height/weight } \\
(\mathrm{m}, \mathrm{kg})(\mathrm{av} \pm \mathrm{SD})\end{array}$ \\
\hline Males & 15 & $35 \pm 10$ & $150.1 \pm 9.1$ & $5.5 \pm 0.8$ & $139 \pm 14.7 / 81.1 \pm 11.2$ & $0.5 \pm 0.4$ & $1.76 \pm 0.1 / 81.9 \pm 11.6$ \\
Females & 15 & $32 \pm 10$ & $132 \pm 5.7$ & $5.9 \pm 1.3$ & $122 \pm 13.4 / 76.8 \pm 7.6$ & $0.3 \pm 0.1$ & $1.67 \pm 0.1 / 67.0 \pm 11.5$ \\
\hline
\end{tabular}

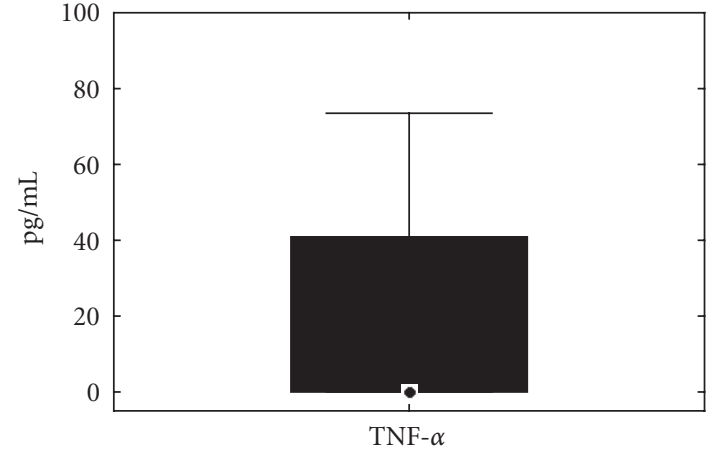
o Median
- Distant values
I Maximum and minimum values
25th-75th percentile Extreme values

(a)

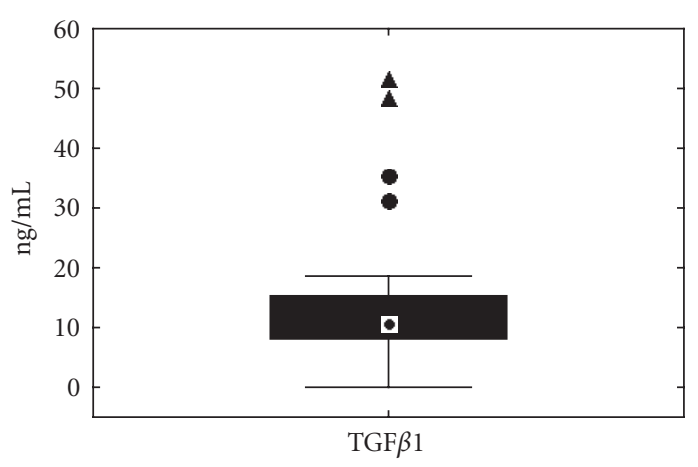

$$
\begin{aligned}
& \text { - Median } \quad \text { 25th-75th percentile } \\
& \text { - Distant values } \\
& \text { I Maximum and minimum values }
\end{aligned}
$$

(b)

FIGURE 2: Plasma concentration of tumor necrosis factor- $\alpha$ (TNF- $\alpha$ ) and transforming growth factor $\beta 1$ (TGF $\beta 1$ ) in the healthy blood donors (box-and-whiskers plot). See the caption in Figure 1.

one of these men also had positive IL-5, CXCL8, and SCD40L levels.

DL for CXCL8 was $7.26 \mathrm{pg} / \mathrm{mL}$. Two men and 3 women were above this limit. In all of them, sIL-6R, sCD23, and TGF $\beta 1$ were also detected. In the women, TNF- $\alpha$ and CD40L were detected, as was IL-13 in one man and IL-5, IL-6 and CD40L in the second man.

DL was $0.66 \mathrm{pg} / \mathrm{mL}$ for interleukin 10 and there was 1 positive woman (at the same time with a positive value for IL-5 and sIL-6R).

IL-13 level above DL $0.99 \mathrm{pg} / \mathrm{mL}$ was determined in 2 men and 1 woman. In all of these, IL-6R, sCD23, and TGF $\beta 1$ were detected; in 1 man CXCL8 and in 1 woman IL-4 were detected, as well.

\section{Tumor necrosis factor- $\alpha$ (TNF- $\alpha$ )}

The median of the TNF- $\alpha$ levels was 0 , with DL $1.65 \mathrm{pg} / \mathrm{mL}$. There was a difference in the TNF- $\alpha$ median in men and women ( 0 versus $26.2 \mathrm{pg} / \mathrm{mL}$ ). The range of measured values is shown in Figure 2.

\section{Transforming growth factor $\beta 1$ (TGF $\beta 1$ )}

The average level of TGF $\beta 1$ concentrations was 14.98, with SD 12.39 and median $10.8 \mathrm{ng} / \mathrm{mL}$. The median was slightly different for men and for women. The DL of the analysis was $0.06 \mathrm{ng} / \mathrm{mL}$. The range of measured values is shown in Figure 2.

\section{Soluble CD23 and CD40L molecules}

The range of levels for sCD23 (DL $3.3 \mathrm{ng} / \mathrm{mL}$ ) was $28.9 \pm$ SD 15.22 with median $27.6 \mathrm{ng} / \mathrm{mL}$, and the median of values for sCD40L with DL $0.062 \mathrm{ng} / \mathrm{mL}$ was 0 (see Figure 3 ). The detected levels in some men and women were present together with positive values for sIL-6R, sCD23, TGF $\beta 1$, and in some cases together with IL-2, IL-5, IL-6, CXCL8, or TNF- $\alpha$.

\section{Soluble receptor for interleukin-6 (sIL-6R)}

For sIL-6R (DL $0.01 \mathrm{ng} / \mathrm{mL}$ ), the average levels were $75.89 \pm$ 35.83 with median $68.75 \mathrm{ng} / \mathrm{mL}$. The range of measured values is shown in Figure 3.

The data analysis included testing for correlations among particular cytokines and co-stimulatory molecules (IL-2-IL13, TNF- $\alpha$, sIL-6-R, sCD23, sCD40L, TGF $\beta 1$ ) against one another using a Spearman order correlation coefficient. Thus 60 tests were performed, but no direct dependence was found among the values (no test showed a significant nonzero correlation for $P=.05)$.

The other factors (gender and blood group, including Rh factor) were tested with a Kolmogorov-Smirnov nonparametric test against the cytokines and costimulatory molecule concentrations. None of the 36 tests proved significance at the $P=.05$ level. Logistic regression models described in the methodology section were used to simulate the effects of 


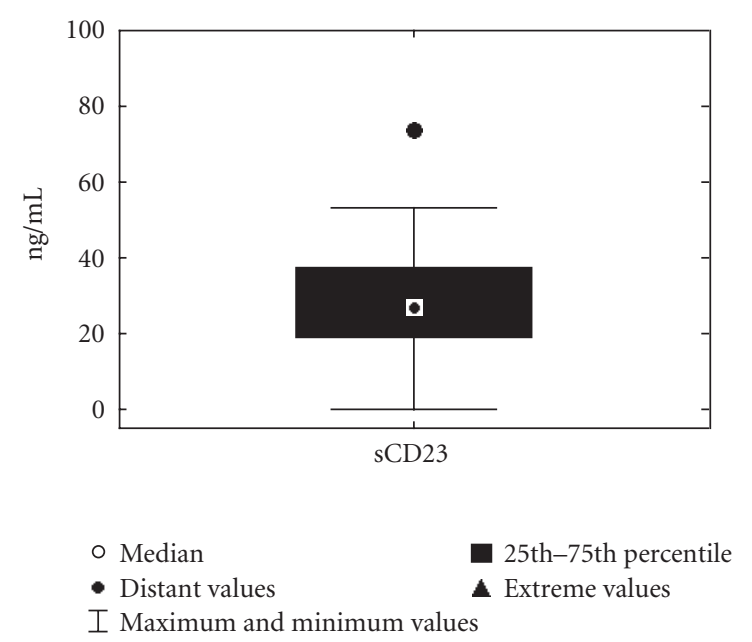

(a)

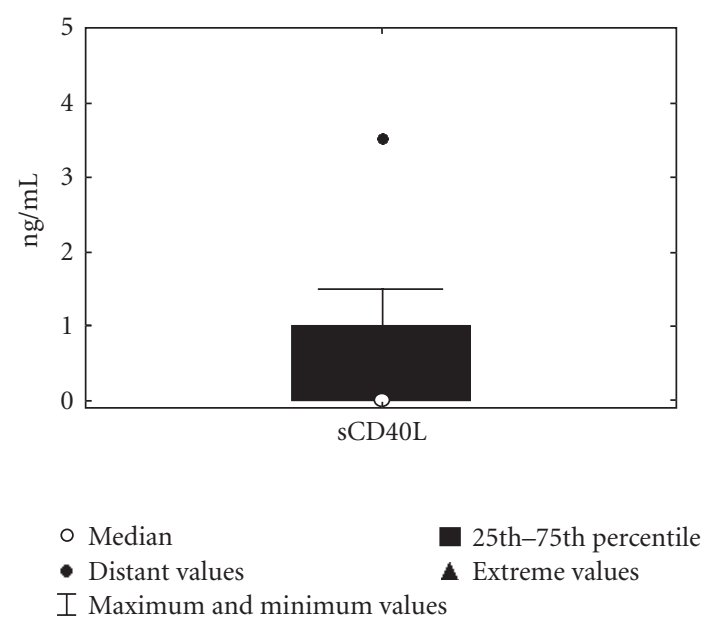

(b)

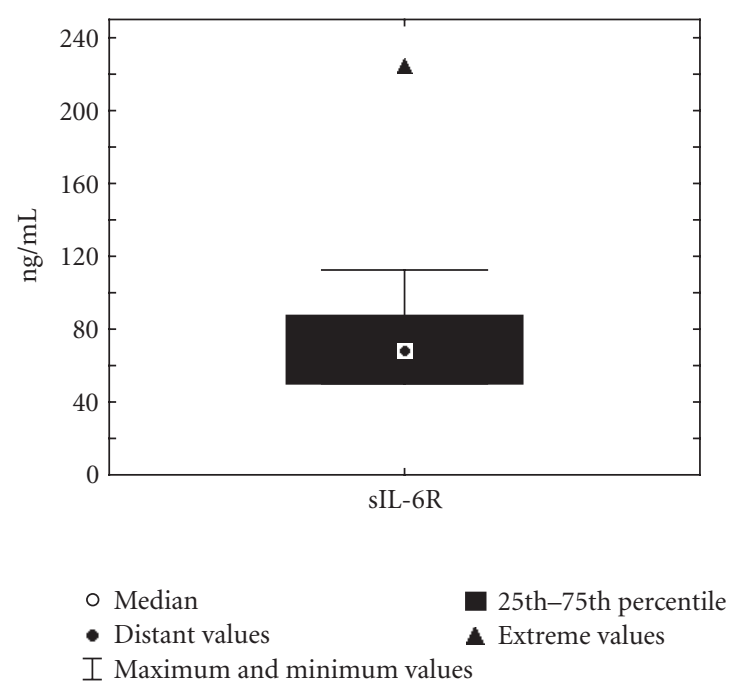

(c)

FIgURe 3: Plasma concentration of soluble CD23, sCD40L, and sIL-6R in the healthy blood donors (box-and-whiskers plot). See the caption in Figure 1.

independent values (gender and blood group) on combinations of cytokines. No significant correlations were found in these models either.

\section{DISCUSSION}

Cytokine concentration in body fluids varies naturally within a certain range influenced by extrinsic and intrinsic factors and depending on age. Most interleukins, unlike their receptors, are not detected in the body fluids of healthy individuals. Although concentrations of cytokines have been measured in the blood of healthy subjects, few reports analyze systematically more than one cytokine in a homogeneous cohort. We used an adequate number of healthy individuals for detecting the physiologic levels of cytokines, knowing as well other blood parameters. We also used a specific statistical ap- proach to analyze the results, which, because of many zerodata values, are scarcely assessable using standard statistical methods. In the text below, we discuss reference values which were described in particular publications to detect cytokine concentration in serum from the peripheral blood of healthy individuals. There is evidence, however, that analyses of cytokine concentration in human plasma instead of serum are more precise, for example, [6].

Interleukin 2 is an example of a cytokine that has been used in clinical oncology in the treatment of renal cell carcinoma and melanoma [7]. Its clinical benefit has been tested in many other indications $[8,9]$. Measurable IL-2 concentrations in the majority of observed samples were not detected.

IL-4 has been regarded as a control for inflammatory mediators' production (TNF- $\alpha, \mathrm{IL}-1, \mathrm{PGE}_{2}$ ) and its clinical 
importance is related, for instance, to the graft versus host disease (GvHD) after allogeneic transplantation of bone marrow. Modification of the donor T-lymphocyte reaction can reduce the risk of relapse and donor cell engraftment failure [10]. sIL-6R, sCD23, TGF $\beta 1$, and IL-13 were simultaneously found, as well, in values above detection limits (DL). The functions of IL-5 are joined with the eosinophiles and B-lymphocytes. The effect of therapy against IL-5 overproduction in hypereosinophilic syndrome and atopic reactions with monoclonal antibody mepolizumab has been described [11]. Together with IFN- $\gamma$, TNF- $\alpha$, and IL-13, this appears to be a significant predictor of acute GvHD development after allogeneic nonrelated donor stem cell transplantation [12], while it should not be detected in healthy individuals. However, $17 \%$ of the tested group of individuals had measurable concentrations of IL-5 in plasma. IL6 significantly modulates the expression of other cytokines and affects those cytokines that participate in tumor growth control. Thomas et al determined an IL-6 concentration of $6 \mathrm{pg} / \mathrm{mL}$ in serum of 10 healthy controls, but no correlation was found between the detected level and age or gender [13]. With DL $0.7 \mathrm{pg} / \mathrm{mL}$, Wierzbowska et al stated the range in serum level for 24 healthy controls at $0.5-$ $16.6 \mathrm{pg} / \mathrm{mL}$ (median 5.35) [14]. Using an analysis with relatively high DL $(10 \mathrm{pg} / \mathrm{mL})$, Gause et al detected serum IL6 levels in only 2 of 20 healthy donors [15]. In other control groups, a median of IL- 6 was $2.6 \mathrm{pg} / \mathrm{mL}$, with a range of $2.03-4.7 \mathrm{pg} / \mathrm{mL}$, or was not detected exactly $[16,17]$. Watanabe et al published the results of observations of the relation between hematopoietic cell mobilization and endogenous productions of CXCL8, MIP- $1 \alpha$, TNF- $\alpha$, and interferon- $\gamma($ IFN $-\gamma)$ in 20 PBSC donors [18]. Only CXCL8 correlated with the $\mathrm{CD}^{+} 4^{+}$cells and CFU-GM (colonyforming unit-granulocyte-macrophage) increase. Its average value before stimulation was $7.1 \mathrm{pg} / \mathrm{mL}$, and after stimulation it increased by as much as 30 times. We discovered production of this chemokine in plasma only in $17 \%$ of blood donors.

The possible utility of cytokines including interleukin 10 and adhesive molecules as prognostic markers in B-CLL has been confirmed [19]. Lu et al showed that IL-10 is a growth factor unrelated to IL-6 for human malignant plasmablastic cells [20]. In this work, there is reference to nonpublished results when IL-10 was not proven in blood even in a large group of healthy individuals $(n=150)$.

The multifunctional effect of IL-13 interferes with the induction of CD23 expression on B-lymphocytes and B-cell proliferation and stimulates $\operatorname{IgE}$ and $\mathrm{IgG}_{4}$ secretion. It has potential application in B-CLL or Hodgkin's disease treatment where IL-13 works as the apoptosis and tumor growth modulator [21]. Another possible application is in allogeneic hematopoietic stem cell transplantation, where the IL-13 level in the graft donors was the most significant predictor of development of GvHD in the transplant recipient [12]. Measurable plasma concentrations were found in $10 \%$ of blood donors.

It has been confirmed that the mononuclear cells from peripheral blood of healthy individuals produce an amount of TNF- $\alpha 10$ times greater than do cells of patients with CLL [6]. In the control volunteers group, TNF- $\alpha$ was under the detection limit. Fuhrmann-Benzakein et al measured values beneath $13 \mathrm{pg} / \mathrm{mL}$ in healthy controls during observation of angiogenic cytokines in patients with solid tumors [22]. Our controls had a median of values equal to 0 , with a maximum value approximately 5 times higher than in the paper mentioned.

$\mathrm{TGB} \beta 1$ has its significance in angiogenesis regulation. Plasma concentrations of angiogenic cytokines (bFGF, HGF, VEGF, TGF $\beta$, and TNF- $\alpha$ ) of 40 healthy volunteers served as reference values in the above-mentioned paper. The median of values for TGF $\beta$ was $16 \mathrm{ng} / \mathrm{mL}$ (range of values 3-40) [22], higher than the median of plasma TGF $\beta 1$ in our control group.

The importance of CD23 antigen has been proven not only in nononcological diseases (diabetes mellitus, asthma), but also as a prediction factor in hairy cell leukemia (HCL) and B-CLL $[23,24]$. An average concentration of $47 \mathrm{ng} / \mathrm{mL}$ (values in a range of 10-91 ng/mL) (manual BenderMedSystems Instant ELISA for hsCD23, 2005) was detected in serum of 8 donors, in agreement with our results. Soluble CD40 ligand is a costimulating molecule involved in growth regulation and T-cell dependent B-lymphocytes survival [25]. Its increased level was found in patients with B-cell lymphomas, as well as with other B-lymphocyte derived malignancies. Healthy controls had detectable serum concentrations, as well.

Concentration of receptor for IL- 6 was increased in patients with various hematooncological diseases that were submitted to IL-2/IFN- $\alpha_{2 a}$ immunotherapy after bone marrow transplantation or donor lymphocyte transfusion, then decreased to normal levels, that is, values of $20 \pm 3 \mathrm{ng} / \mathrm{mL}$ [26]. According to the available data, the concentration of sIL-6R can reach values from 65 to more than $200 \mathrm{ng} / \mathrm{mL}$ in the serum of healthy individuals. The median of values in our group of donors was $67.75 \mathrm{ng} / \mathrm{mL}$.

The immunopotention and immunoregulation effects of cytokines are a subject of interest for extensive research. The relations between cytokine levels and stages of various oncological and nononcological diseases are being observed, as well as their significance in response to appropriate therapy.

Nonparametric statistical tests and logistic regression models were used to test for possible correlations among measured data, including combination of cytokines. We did not find correlations between plasma levels of interleukins, sIL-6R, sCD23, sCD40L, TNF- $\alpha$, TGF $\beta 1$, and gender or among cytokines themselves. Nor was there correlation between concentrations of the cytokines and blood groups or Rh factor of the blood donors. Other routinely performed laboratory tests (including white blood cells count, hemoglobin concentration, hematocrit, level of transaminases) did not correspond with elevated plasma levels of detected cytokines. Because concentration of cytokines is often below the measurable level in plasma of healthy subjects, however, our work describes a specific approach for handling the problem of zero-values data. The probability of occurrence of positive value was calculated in the blood donor 
group for each particular interleukin, which was measured in blood plasma.

\section{ACKNOWLEDGMENT}

This work was supported by Grant IGA MZ CR NR8003-3/ 2004.

\section{REFERENCES}

[1] Thomson AW, Lotze MT, eds. The Cytokine Handbook. 4th ed. London, UK: Academic Press; 2003.

[2] Singhal S, Powles R, Treleaven J, Horton C, Mehta J. Longterm safety of GM-CSF (molgramostim) administration after allogeneic bone marrow transplantation for hematologic malignancies: five-year follow-up of a double-blind randomized placebo-controlled study. Leukemia and Lymphoma. 1997;24(3-4):301-307.

[3] Chiang K-Y, Lamb L, Clark J, Worthington-White D, Rich I, Henslee-Downey PJ. Assessment of G-CSF stimulated BM hematopoietic stem cells in normal donors. Cytotherapy. 2002;4(1):55-63.

[4] Bewtra M, Lichtenstein GR. Infliximab use in Crohn's disease. Expert Opinion on Biological Therapy. 2005;5(4):589-599.

[5] Etemad L, Yu EB, Wanke LA. Dose adjustment over time of etanercept and infliximab in patients with rheumatoid arthritis. Managed Care Interface. 2005;18(4):21-27.

[6] Foa R, Massaia M, Cardona S, et al. Production of tumor necrosis factor-alpha by B-cell chronic lymphocytic leukemkia cells: a possible regulatory role of TNF in the progression of the disease. Blood. 1990;76(2):393-400.

[7] Eklund JW, Kuzel TM. Interleukin-2 in the reatment of renal cell carcinoma and malignant melanoma. Cancer Treatment and Research. 2005;126:263-287.

[8] Hsu W, Lesniak MS, Tyler B, Brem H. Local delivery of interleukin-2 and adriamycin is synergistic in the treatment of experimental malignant glioma. Journal of Neuro-Oncology. 2005;74(2):135-140.

[9] Meloni G, Vignetti M, Andrizzi C, Capria S, Foa R, Mandelli F. Interleukin-2 for the treatment of advanced acute myelogenous leukemia patients with limited disease: updated experience with 20 cases. Leukemia and Lymphoma. 1996;21(56):429-435.

[10] Krenger W, Ferrara JLM. Dysregulation of cytokines during graft-versus-host disease. Journal of Hematotherapy. 1996; $5(1): 3-14$.

[11] Garrett JK, Jameson SC, Thomson B, et al. Anti-interleukin5 (mepolizumab) therapy for hypereosinophilic syndromes. Journal of Allergy and Clinical Immunology. 2004;113(1):115119.

[12] Jordan WJ, Brookes PA, Szydlo RM, Goldman JM, Lechler RI, Ritter MA. IL-13 production by donor $\mathrm{T}$ cells is prognostic of acute graft-versus-host disease following unrelated donor stem cell transplantation. Blood. 2004;103(2):717-724.

[13] Thomas X, Hirschauer C, Troncy J, et al. Serum interleukin6 levels in adult acute myelogenous leukemia: relationship with disease characteristics and outcome. Leukemia and Lymphoma. 1997;24(3-4):291-300.

[14] Wierzbowska A, Urbańska-Ryś H, Robak T. Circulating IL-6type cytokines and sIL-6R in patients with multiple myeloma. British Journal of Haematology. 1999;105(2):412-419.
[15] Gause A, Spickermann D, Klein S, Diehl V, Pfreundschuh M. Elevation of circulating IL-6 in patients with acute nonlymphocytic leukemia. European Journal of Haematology. 1994;53(3):178-180.

[16] Lai R, O’Brien S, Maushouri T, et al. Prognostic value of plasma interleukin-6 levels in patients with chronic lymphocytic leukemia. Cancer. 2002;95(5):1071-1075.

[17] Herold M, Schmalzl F, Zwierzina H. Increased serum interleukin 6 levels in patients with myelodysplastic syndromes. Leukemia Research. 1992;16(6-7):585-588.

[18] Watanabe T, Kawano Y, Kanamaru S, et al. Endogenous interleukin-8 (IL-8) surge in granulocyte colony-stimulating factor-induced peripheral blood stem cell mobilization. Blood. 1999;93(4):1157-1163.

[19] Kamper EF, Papaphilis AD, Angelopoulou MK, et al. Serum levels of tetranectin, intercellular adhesion molecule- 1 and interleukin-10 in B-chronic lymphocytic leukemia. Clinical Biochemistry. 1999;32(8):639-645.

[20] Lu ZY, Zhang XG, Rodriguez C, et al. Interleukin-10 is a proliferation factor but not a differentiation factor for human myeloma cells. Blood. 1995;85(9):2521-2527.

[21] Wynn TA. IL-13 effector functions. Annual Review of Immunology. 2003;21:425-456.

[22] Fuhrmann-Benzakein E, Ma MN, Rubbia-Brandt L, et al. Elevated levels of angiogenic cytokines in the plasma of cancer patients. International Journal of Cancer. 2000;85(1):40-45.

[23] Sarmiento MA, Palacios MF, Scolnik MP, et al. Evolution of chronic lymphocytic leukemia. Predictive value of immunophenotype, sCD23 and morphology. Medicina. 2002; 62(4):305-312.

[24] Schwarzmeier JD, Shehata M, Hilgarth M, et al. The role of soluble CD23 in distinguishing stable and progressive forms of B-chronic lymphocytic leukemia. Leukemia and Lymphoma. 2002;43(3):549-554.

[25] Clodi K, Asgary Z, Zhao S, et al. Coexpression of CD40 and CD40 ligand in B-cell lymphoma cells. British Journal of Haematology. 1998;103(1):270-275.

[26] Toren A, Novick D, Ackerstein A, Or R, Slavin S, Nagler A. Soluble IL-6 receptors (sIL-6R) in hematological patients receiving immunotherapy with IL-2/IFN- $\alpha$ or donor lymphocytes following bone marrow transplantation. Bone Marrow Transplantation. 1996;18(4):721-724. 


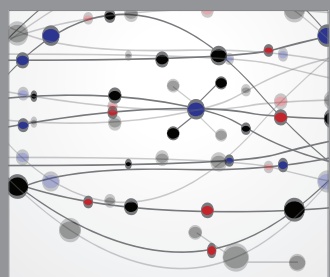

The Scientific World Journal
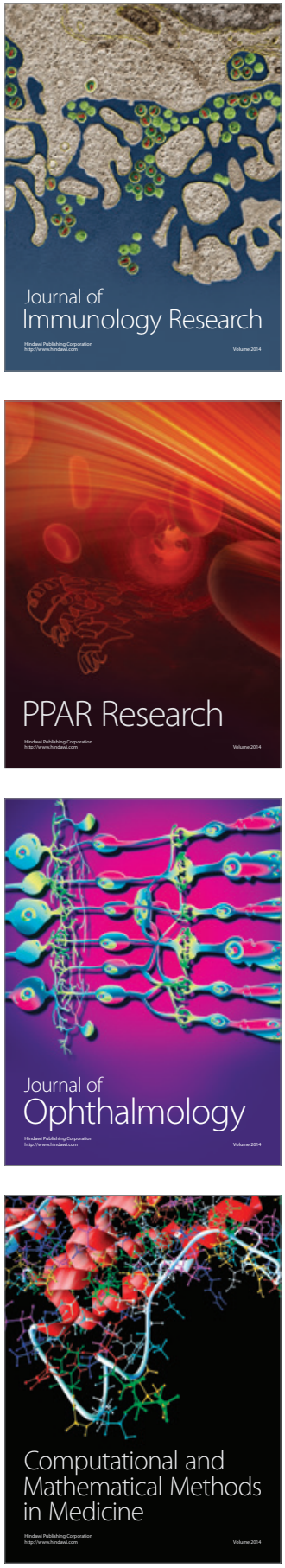

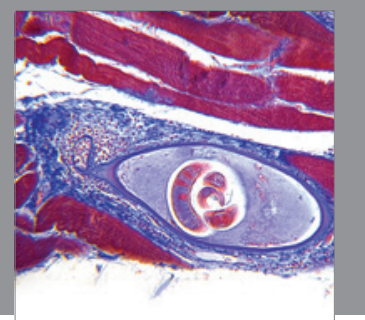

Gastroenterology

Research and Practice
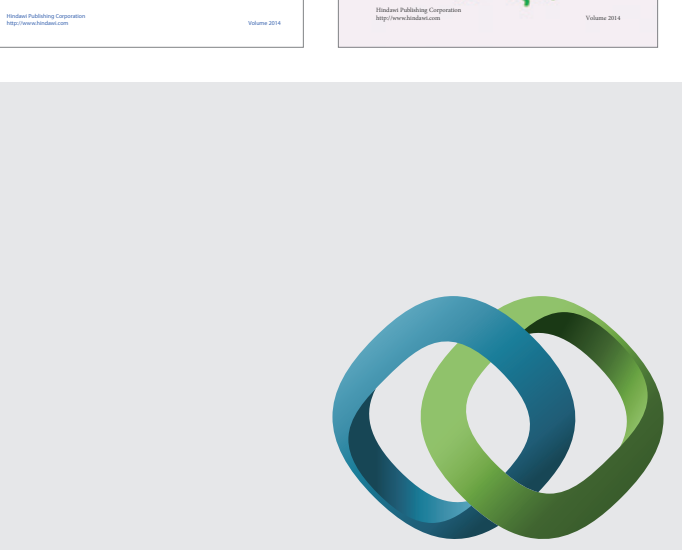

\section{Hindawi}

Submit your manuscripts at

http://www.hindawi.com
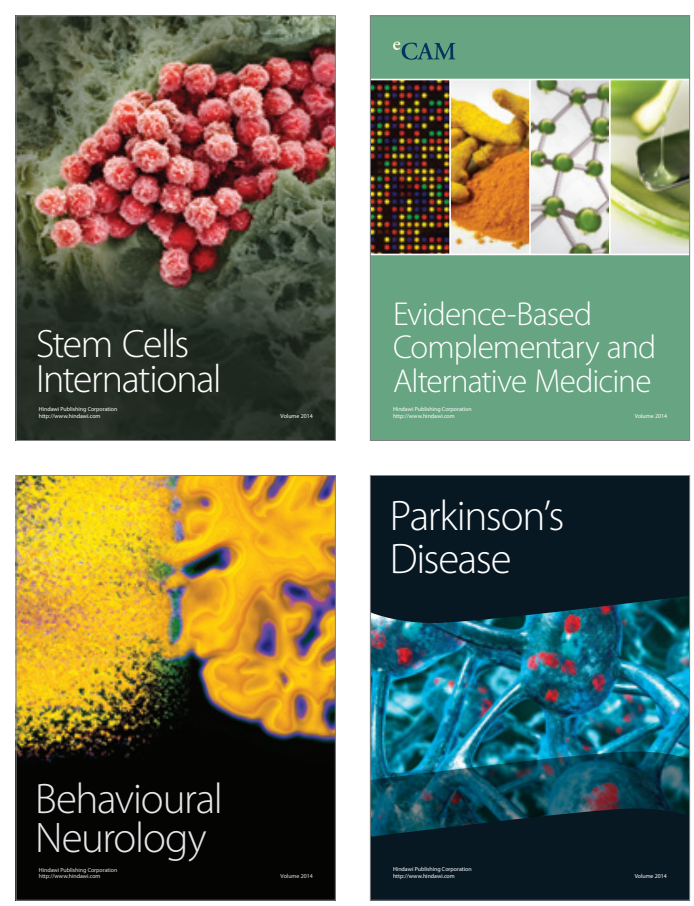

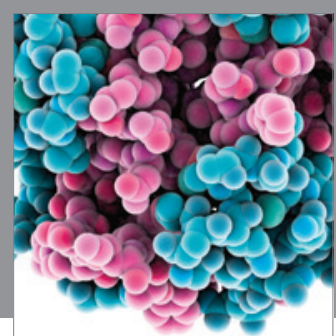

Journal of
Diabetes Research

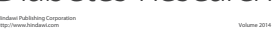

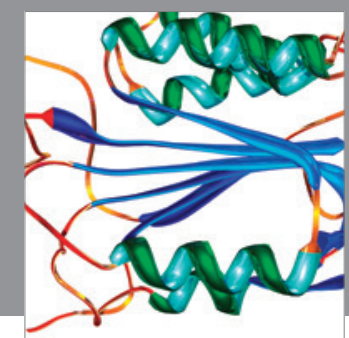

Disease Markers
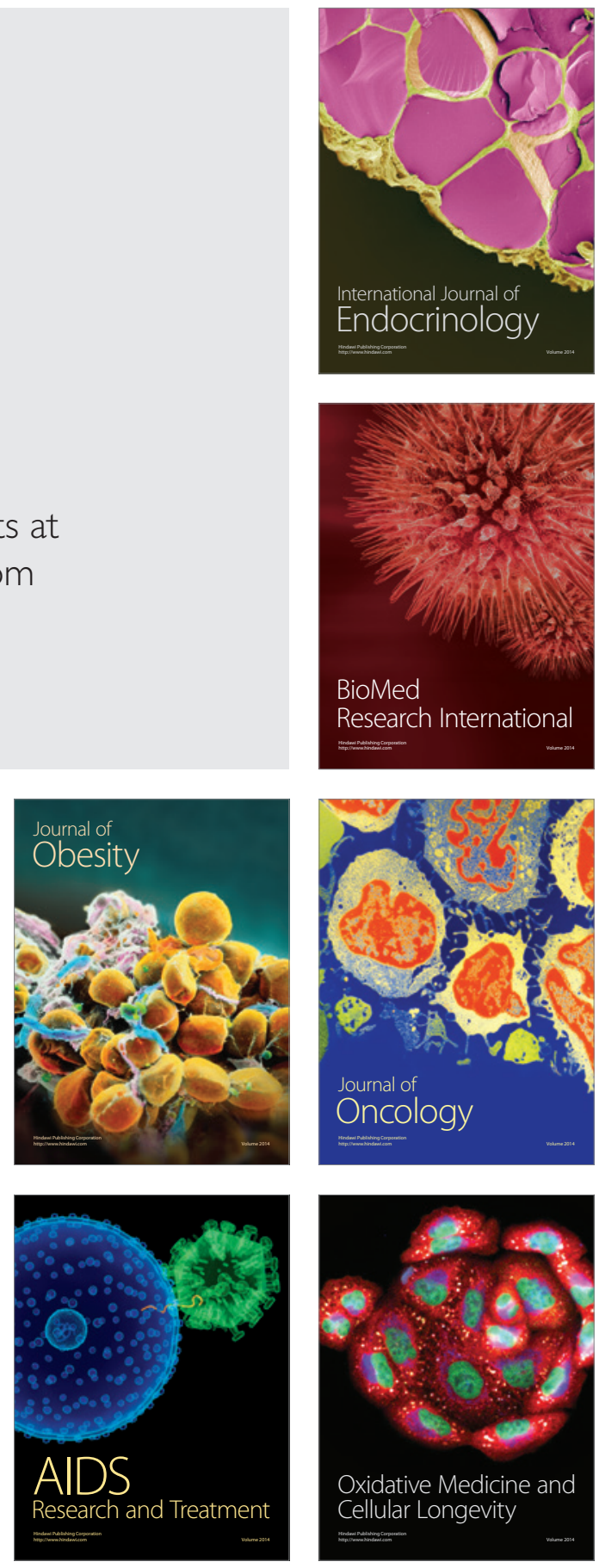